\title{
RECOMMENDATIONS FOR MANAGING EQUIPMENT AGING IN NUCLEAR POWER PLANTS ${ }^{1}$
}

\author{
W. E. Gunther and M. Subudhi \\ Brookhaven National Laboratory \\ and \\ S. K. Aggarwal \\ U.S. Nuclear Regulatory Commission
}

BNL-NUREG- -48034

DE93 004651

\begin{abstract}
Research conducted under the auspices of the U.S. NRC's Nuclear Plant Aging Research (NPAR) Program has resulted in a large database of component and system operating, maintenance, and testing information ${ }^{1}$. This database has been used to determine the susceptibility to aging of selected components, and the potential for ecripment aging to impact plant safety and availability. It has also identified methods for detecting and mitigating component and system aging. This paper describes the research recommendations on electrical components which could be applied to maintenance, testing, and inspection activities to detect and mitigate the effects of aging prior to equipment failures.
\end{abstract}

\section{Introduction}

A review has been conducted of the results achieved from aging research performed by the $\mathrm{NRC}^{2}$. These results have direct application to inspection and operating personnel responsible for assuring the safety of the plant over its operating life. The types of information needed to effectively manage aging which are presented in aging research results include:

1. Identification of materials and components susceptible to age-related degradation.

2. The determination of operating stresses which contribute to the aging process, especially those associated with the equipment's normal environment.

3. An assessment of operating experience to validate the dominant failure modes, causes and effects, and the interaction of the equipment with safety systems.

4. Recommended inspection, surveillance, maintenance and monitoring techniques useful for detecting and mitigating the effer.s of aging.

5. Estimates of service life or probability of failure variation with time.

In addition to the technical results achieved in the
NPAR Program which are useful for managing aging, programmatic aspects have also been evaluated. For example, because a plant's maintenance program is the principal vehicle through which age-related degradation is managed, the Maintenance Team Inspection (MTI) reports compiled by the NRC staff between 1988 and 1991 have been appraised from an aging perspective ${ }^{3}$. These reports provide substantial information on how plant maintenance programs address the aging of systems, components, and structures. This information includes the attitude of management toward the aging issue and the specific maintenance program attributes which address the detection or mitigation of degradation caused by aging.

More than one hundred and twenty five reports have been published through the NPAR Program which address the susceptibility to aging of important components and systems in nuclear power plants. Some of these are related to electrical equipment. From these studies, report summaries and aging assessment guides have been developed for selected safety related equipment susceptible to aging degradation. These summaries and guides represent one method of advising plant personnel of important aging-related issues which need to be addressed in the plant maintenance program. Means of detecting degradation are provided, as well as recommendations for managing aging through maintenance, operations, and engineering activities. Examples of the information from aging research which have been determined to be of immediate application are described in this paper, with the emphasis placed on maintenance activities.

\section{Discussion}

At the end of 1989, the United States had 108 reactors in commercial operation. By the year 2014, forty-eight of these plants will have been operating for forty years. As the population of commercial nuclear power plants has

1 This work done

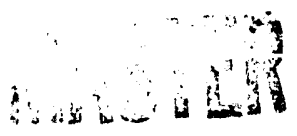




\section{DISCLAIMER}

This report was prepared as an account of work sponsored by an agency of the United States Government. Neither the United States Government nor any agency thereof, nor any of their employees, makes any warranty, express or implied, or assumes any legal liability or responsibility for the accuracy, completeness, or usefulness of any information, apparatus, product, or process disclosed, or represents that its use would not infringe privately owned rights. Reference herein to any specific commercial product, process, or service by trade name, trademark, manufacturer, or otherwise does not necessarily constitute or imply its endorsement, recommendation, or favoring by the United States Government or any agency thereof. The views and opinions of authors expressed herein do not necessarily state or reflect those of the United States Government or any agency thereof. 
matured, the need to disseminate the results obtained through programs such as the NPAR Program has increased.

Aging, if it is not properly managed, affects the operational safety of reactor components, systems, and structures, and as a result can adversely affect public health and safety. Therefore, understanding the aging processes that occur in electrical components is essential so that they can be effectively managed. Research has been completed on several electrical components and systems by contractors to the NRC, primarily the national labs. In a document compiled by BNL entitled "Insights Gained from Aging Research", input was provided by the NRC contractor who performed the research. This was used to deveiop report summaries and assessment guides. For the electrical component and system studies, the following summaries and guides exist:

Battery Chargers, Inverters, Motors, Motor Control Centers, Batteries, Class IE Distribution System, Solenoid Operated Valves, Motor Operated Valves, and Emergency Diesel Generators.

Aging can be accelerated by inadequate maintenance, improper or too frequent testing, or excessive cycling from routine or abnormal operations. An effective maintenance program must address time dependent, age-related degradations associated with risk significant components and systems so as to maintain the safety envelope in operating nuclear power plants of all ages. The important elements of a maintenance program which are needed to effectively manage aging in nuclear power plants are:

- predictive maintenance techniques

- condition monitoring methods

- trending of aging parameters

- root cause analysis of each failure report

- reliability analyses to monitor the aging management program

Specific techniques related to managing the aging of electrical components in nuciear power plants have been recommended by NPAR or were revealed during the assessment of MTI reports. The salient features associated with electrical components are discussed in the ensuing sections.

\section{Electrical Component Assessments}

Emergency Diesel Generators (EDGs): The evaluation of multiple data bases completed during the NPAR research showed that more than $50 \%$ of the failures were attributed to aging. Different aging mechanisms are present, related to the operating status of the system. While in standby, the aging mechanisms are: - corrosion,

- set point drift,

- chemical attack from fuel and lube oils, and environment, dust, and microbial growth. While the system is operating, the aging mechanisms include:

- vibration,

- thermal and mechanical shock,

- excessive operating loads, and

- operating environment.

Operational aging stressors are enhanced by the synergistic influences of current technical specification requirements with respect to cold starts and engine loading. NPAR Program researchers recommended a monthly 'health checkup' to assure operational readiness. The monthly testing program should be redirected to monitor data on about 25 EDG operating parameters that could indicate degraded performance or impending component failure.

EDG system management changes that would result in the most beneficial engine improvements for aging mitigation are:

significantly reduce the number of system starts,

gradually add load during test sequences,

- increase EDG start time to 25-30 second range,

eliminate short run times and excessive idle time, and

include trending of the important engine and generator operating parameters in the aging management progian.

The Mit reports described a large percentage of the failures of the EDG to be associated with the air start system. Other age-related problems include degradation of the motor for the jacket cooling water pumps and degraded starting logic components. In general, the Mil reports indicated that utility $P M$ activities were comprehensive. Condition monitoring techniques being practiced included monitoring of the exhaust gas, chenical analysis of the water vapor in the lube oil, and vibration analysis. However, root eause analysis and trending were generally weak.

Motor Control Centers (MCCs): The most frequent cause of failure is the buildup of dirt or other foreign substances that cause the electrical device to stick. Other aging-related issues presented in the Insights document are :

1. More failures occurred in systems that function intermittently rather than continuously.

2. The starter contactor may fail to close due to a nonuniform magnetic driving force caused by impeded armature motion.

3. Setpoint drift and contact surface degradation are (wo dominant aging-related failure modes.

Several tests are useful in assessing the performance characteristics of the MCC, such as:

- Performing a continuity lest following repair ur replacement of a component.

- Checking mechanical and electrical properties (1) contactors, including verification of pickup and dropout voltages.

- Verifying circuit breaker trip setpoints and comparing the timing with manufacturer's data. 
A recent study on breakers and relays found that the current activities for mitigating aging in breakers and relays could be improved by performing monitoring techniques such as infrared thermography, vibration signature analysis, and inrush current signature measurements ${ }^{5}$.

Motor Operated Valves (MOVS): The NPAR Program research concluded that several segments of the MOV are susceptible to age-related degradation. These sites and the corresponding aging mechanisms are:

- Motor Operator Gearbox Assembly: Gear wear, fastener loosening, stem nut wear, and spring pack response change.

- Motor Operator Switches: Contact pitting, corrosion, electrica! insulation breakdown, and grease hardening.

- Electric Motor Assembly: Bearing wear, corrosion, and electrical insulation breakdown.

MOVs are also known to be adversely affected by inappropriate maintenance such as incorrect stem packing tightness, incorrect torque/limit switch settings, insufficient or excessive lubrication, and an incorrectly installed spring pack.

The MTI reports discussed a number of aging-related problems associated with MOVs. These include the corrosion of body parts and fasteners, flange packing leaks, worn or broken internal parts, and motor burnouts. These reports also addressed some of the techniques being used to address aging.

For example, at each refueling outage many plants clean electrical components, lubricate moving parts, clean and lubricate the gear box, operate torque switches, and megger the motor. In several cases, an overhaul program is implenented which includes replacing worn parts, lubricating the assembly, and testing the equipment. Very few cases were identified where trending or root cause analysis was performed on MOVs.

\section{Conclusions and Recommendations}

Research on the significance of aging on the reliability of key electrical components has been completed. Specific recommendations have been made based on this research that may be helpful in developing a program to effectively manage aging in nuclear power plants. These recommendations have been compiled in NUREG/CR5643, "Insights Gained From Aging Research" for the following electrical components: batteries, battery chargers, cables, emergency diesel generators, inverters, motors, motor control centers (MCCs), motor operated valves (MOVs), and solenoid operated valves (SOVs). A revision to this document will be made to include research results and recommendations for circuit breakers, relays, transformers, surge arrestors, and electrical penetrations.

This paper has summarized the research results for three electrical components; emergency diesel generators, motor control centers, and motor operated valves. In addition, pertinent information from the NRC's MTI reports related to these components has been evaluated to ascertain the strengths and weaknesses of utility electrical maintenance programs in the area of aging management.

From these assessments, it is concluded that sufficient information exists to establish a program which will detect and mitigate the effects of the aging of electrical components. However, it is observed from the evaluation of the MTI reports that additional work must be completed by utility organizations to incorporate these techniques into their maintenance programs. This conclusion is reached by considering the overall lack of specific aging management programs and notable deficiencies in preventive and predictive maintenance, trending, and root cause analysis.

Utilities may want to consider evaluating the insights presented in NUREG/CR-5643 for their specific equipment. Enhancements in the areas of maintenance, testing, and operations as described in the above document will provide the basis for an effective program for managing aging.

\section{References}

1. NUREG-1144, Rev. 2, Nuclear Plant Aging Research (NPAR) Program, June 1991.

2. Gunther, W. and Subudhi, M., eds., "Insights Gained from Aging Research", NUREG/CR-5643, March, 1992.

3. Fresco, A., et. al., "Managing Aging in Nuclear Power Plants: Insights Gained from NRC Maintenance Team Inspection Reports", NUREG/CR-5812, Draft.

4. Kondic, N. and Hill, E., "NRC Research Program "II Plant Aging: Listing and Summaries of Reports Issucd Through June 1991," NUREG-1377, Rev. 2, July, 1941

5. Gleason, J.F., "Comprehensive Aging Assessment it Circuit Breakers and Relays, Phase II," NUREG; ( 'R. 5762, February, 1992. 

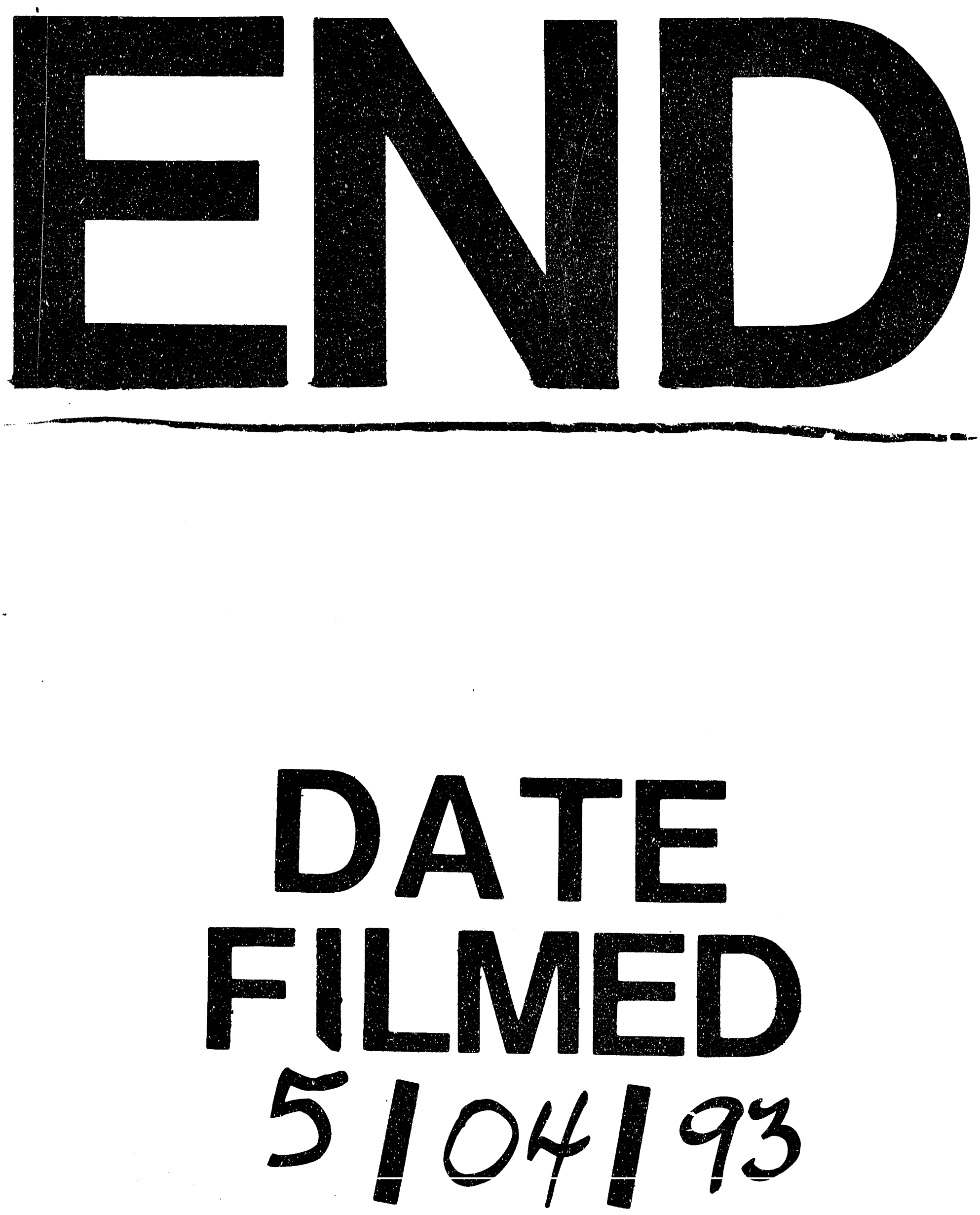


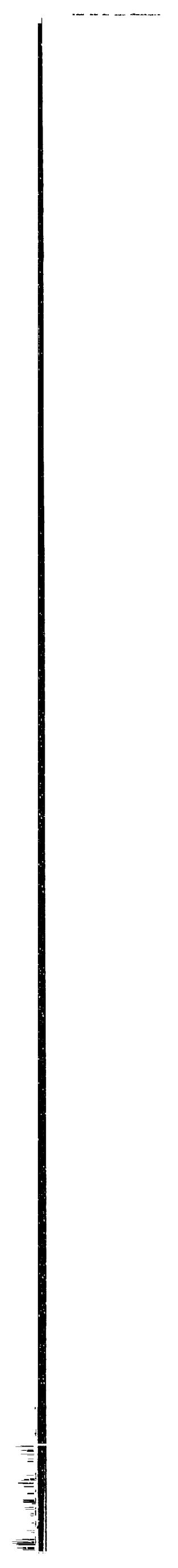

